\title{
Magnitude of Deaths due to Organophosphorus Compounds Poisoning in Bangladesh-A Study at Dhaka Medical College.
}

\author{
Akber EB ${ }^{1}$, Forhad $\mathrm{AJ}^{2}$, Chowdhury $\mathrm{MH}^{3}$, Anam $\mathrm{AMA}^{4}$, Jahan $\mathrm{I}^{5}$
}

\begin{abstract}
Poisoning with Organophosphorus compounds (OPC) is one of the important leading causes of morbidity and mortality for the countrymen of Bangladesh. OPC poisoning is a common cause of acute poisoning. The study was conducted to evaluate the magnitude of death due to OPC poisoning. This paper presents the study of total 852 cases of poisoning comprising $6.42 \%$ of the total 13,300 autopsies done during the period of three years (from 01/01/2009 to 31/12/2011) at Dhaka Medical College Mortuary. Of them, there were 478 cases of OPC poisoning. Most of the victims were from rural areas i.e 296 cases $(61.92 \%)$ and 182 cases $(38.07 \%)$ from urban areas. 274 male victims (57.32\%) outnumbered females i.e 204 cases $(42.67 \%)$ and the most affected age group was $21-30$ years i.e 214 cases $(44.76 \%)$ ). Farmers were the commonest victim i.e 270 cases $(56.48 \%)$ followed by housewives i.e 105 cases $(21.96 \%)$. Ingestion was the commonest route of poisoning i.e 460 cases comprising $96.23 \%$ followed by 12 cases of inhalation $(2.51 \%)$ and others. Suicide dominated the list of manner of death i.e 466 cases comprising $97.48 \%$ followed by accidental i.e 12 cases $(2.51 \%)$ of the total 478 cases of OPC poisoning.
\end{abstract}

CBMJ 2014 July: Vol. 03 No. 02 P: 29-33

Key Words: Poisoning, Organophosphorus Compounds, Death, Postmortem Examination.

\section{Introduction}

We can define poison as "A substance either solid, liquid or gaseous, which if introduced in the living body, or brought into contact with any part thereof will produce ill-health or death, by its constitutional or local effects or both ${ }^{1}$. Poisoning occurs when any substance interferes with normal body functions after it is swallowed, inhaled, injected or absorbed ${ }^{2}$. Poisoning may be of four types namely-Fulminant, Acute, Chronic and Subacute $^{3}$.

Organophosphorus Compounds (OPC) cause toxicity after their absorption from the skin, mucous membrane and respiratory tract following accidental exposures, or from gastrointestinal tract following suicidal ingestion. They are metabolically subjected to hydrolysis by esterase although they bind to and interact with a number of enzymes, Acetyle Cholinesterase (Ach E) that is of clinical importance ${ }^{4}$. OPCs are deadly toxic to human beings, as they are also most effective as insecticidal agents. Hence, these preparations are most popular on one side and also takes many lives every year ${ }^{5}$. Since man has started agriculture, he has been troubled by insects. He has been using insecticides since ages. Organophosphates were introduced in 1854 as pesticides but their toxicity was not known till $1931^{6}$.

1. *Dr. Elias Bin Akber Assistant Professor Department of Forensic Medicine Shaheed Monsur Ali Medical College Uttara, Dhaka.

2. Dr. Abu Jamil Forhad Professor and Head, Department of Forensic Medicine, Shaheed Monsur Ali Medical College, Uttara, Dhaka.

3. Dr. Mohammad Habibuzzaman Chowdhury Professor and Head Department of Forensic Medicine, Dhaka Medical College, Dhaka.

4. Dr. A.M. Ashraful Anam Assistant Professor, Department of Forensic Medicine, Dhaka Central International Medical College, Ring Road, Shyamoli, Dhaka.

5. Dr. Israt Jahan Ex Lecturer Department of Pathology Shahab Uddin Medical College, Gulshan Dhaka.

- Address of Correspondence: Email : eliasbinakber@gmail.com Phone: +8801840444434 
Bangladesh is a developing country in South Asia. Rural population of this country mostly depend on agriculture. With the advance of times, insecticides and pesticides are in use routinely now-a days for modern method of cultivation. These are readily available as over the counter (OTC) drugs in the rural shops and act as a common agent for suicidal purpose after trivial, familial or emotional problems ${ }^{7,8}$.

The number of intoxication with OPCs is estimated at some $3,000,000$ per year, fatality rates of $20 \%$ are common and the World Health Organization (WHO) has estimated that 2,00,000 people die each year from pesticides poisoning ${ }^{9}$. Acute poisoning is one of the important causes of morbidity and mortality worldwide. OPCs are commonly used insecticides and form the most frequent cause of poisoning in agricultural communities ${ }^{10}$. Our aims and objectives for this research work is to study the incidence of Organophosphorus Compounds Poisoning and to analyze the patterns and social factors in relation to this poisoning.

\section{Methods}

This is a retrospective cross sectional study carried out at Dhaka Medical College Mortuary during the period of three years from $01 / 01 / 2009$ to $31 / 12 / 2011$. Subjects were selected from the postmortem cases. During that period 13,300 postmortem examinations were done, which were then analyzed under various parameters such as number of poisoning cases with OPC along with areawise distribution, occupational distribution, age and sex-wise distribution, probable causes of taking OPC, route of administration and manner of death. Information was achieved from the relatives or accompanying persons of the deceased, Investigating Police Officer, Inquest Report, Hospital Records and Postmortem Register Books of Forensic Medicine \& Toxicology Department of Dhaka Medical College. History of the cases were studied in detail, then thorough and medicolegal autopsy was done on each of these cases. Routine preservation of the viscera was done by using appropriate preservatives and then sent to the Chief Chemical Examiner's Office at Mohakhali for chemical analysis. Then final opinion regarding the causes of death were given. The given data have been calculated and analyzed manually.

\section{Results}

Most of the cases were observed in the year 2010 among the three years case study i.e 318 cases $(7.06 \%)$ out of the total number of 4500 Post-mortem examinations performed in that year (Table-1). During the Study, it was seen that the incidence of poisoning was increased in 2010 (318 cases) in comparison with 290 cases of poisoning $(6.9 \%)$ of the total 4200 Post-mortem examinations studied in the year 2009. Then after 2010, there was a decline in the number of poisoning cases i.e 244 cases $(5.3 \%)$ of the total 4600 postmortem examinations in 2011 (Table-1).

Out of the total 852 cases of poisoning, 478 cases were of OPC poisoning comprising $56 \%$ of the total (Figure-1)

Majority of the cases of OPC poisoning were from rural areas i.e 296 cases comprising $61.92 \%$ and 182 cases were from urban areas comprising $38.07 \%$ (Figure-2).

Most of the victims were male i.e 274 cases comprising $57.32 \%$ and there were 204 female victims comprising $42.67 \%$ of the total (Table-2).

The most affected age group was $21-30$ years of life for both sexes i.e 214 cases comprising $44.76 \%$ followed by the age group $12-20$ years i.e 128 cases $(26.77 \%), 82$ cases (17.15\%) from $31-40$ years, 40 cases $(8.36 \%)$ from $41-50$ years, 8 cases (1.67\%) from $51-60$ years and 6 cases from the age group of 60 years and above comprising $1.25 \%$ of the total 478 cases of OPC poisoning (Table-2).

During distribution of the cases according to occupation, our observation was that, the farmers were the commonest victim i.e 270 cases comprising $56.48 \%$ followed by housewives in 105 cases (21.96\%), day 
laborers in 55 cases (11.5\%), service holders in 20 cases $(4.18 \%)$, students in 16 cases $(3.34 \%)$, businessman in 12 cases comprising $2.51 \%$ of the total of 478 cases of OPC poisoning (Figure-3).

Family conflict was the commonest cause of taking OPC which contributed 263 cases comprising $55.02 \%$ followed by marital disharmony in 131 cases $(27.40 \%)$, economic hardship in 33 cases $(6.9 \%)$, dowry deaths in 14 cases ( $2.92 \%$ ), failure of love in 12 cases $(2.51 \%)$, unemployment in 10 cases $(2.09 \%)$, scolding from elder person and guardians in 8 cases $(1.67 \%)$, during spraying as insecticides in 4 cases $(0.83 \%)$, psychiatric illness in 2 cases $(0.41 \%)$ and no cause could be detected in 1 case comprising $0.20 \%$ of the total 478 cases (Figure -4 )

Regarding route of poisoning, we observed ingestion (oral route) was on top of the list i.e 460 cases comprising $96.23 \%$ followed by inhalation in 12 cases $(2.51 \%)$ and combination of ingestion and inhalation in 6 cases comprising $1.25 \%$ of the total 478 cases (Figure - 5).

Suicide outnumbered the list of manner of death i.e we observed 466 cases of suicide comprising $97.48 \%$ followed by accidental in 12 cases comprising $2.51 \%$ of the total. No case of homicide was found with OPC poisoning (Figure -6).

Table-1 : Year-wise distribution of the total number of poisoning cases.

\begin{tabular}{|c|c|c|c|}
\hline Year & $\begin{array}{c}\text { Total Number of } \\
\text { P.M Examination }\end{array}$ & $\begin{array}{c}\text { Total No. of } \\
\text { Poisoning } \\
\text { Cases }\end{array}$ & Percentage \\
\hline 2009 & 4200 & 290 & $6.9 \%$ \\
\hline 2010 & 4500 & 318 & $7.06 \%$ \\
\hline 2011 & 4600 & 244 & $5.3 \%$ \\
\hline Total & 13300 & 852 & $6.42 \%$ \\
\hline
\end{tabular}

Table-2: Age and sex wise distribution of the total number of Organophosphorus Compound Poisoning

\begin{tabular}{|l|c|c|c|}
\hline & Male & Female & Total \\
\hline $12-20$ & $79(28.83 \%)$ & $49(24.01 \%)$ & $128(26.77 \%)$ \\
\hline $21-30$ & $132(48.17 \%)$ & $82(40.19 \%)$ & $214(44.76 \%)$ \\
\hline $31-40$ & $40(14.59 \%)$ & $42(20.58 \%)$ & $82(17.15 \%)$ \\
\hline $41-50$ & $15(5.47 \%)$ & $25(12.25 \%)$ & $40(8.36 \%)$ \\
\hline $51-60$ & $5(1.82 \%)$ & $3(1.47 \%)$ & $8(1.67 \%)$ \\
\hline$\rightarrow 60$ & $3(1.09 \%)$ & $3(1.47 \%)$ & $6(1.25 \%)$ \\
\hline Total & $274(57.32 \%)$ & $204(42.67 \%)$ & $478(100 \%)$ \\
\hline
\end{tabular}

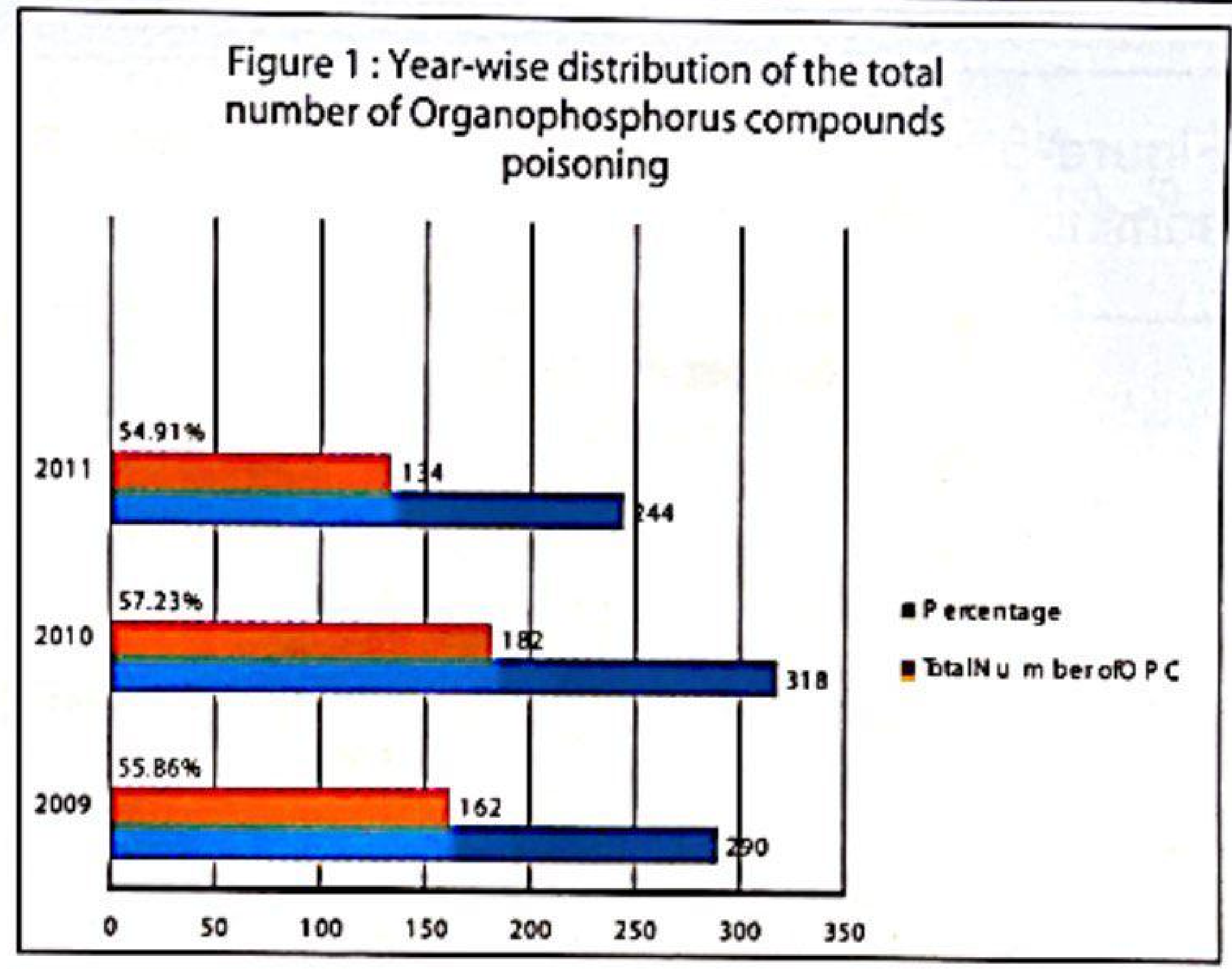

Figure 2: Area-wise distribution of the total

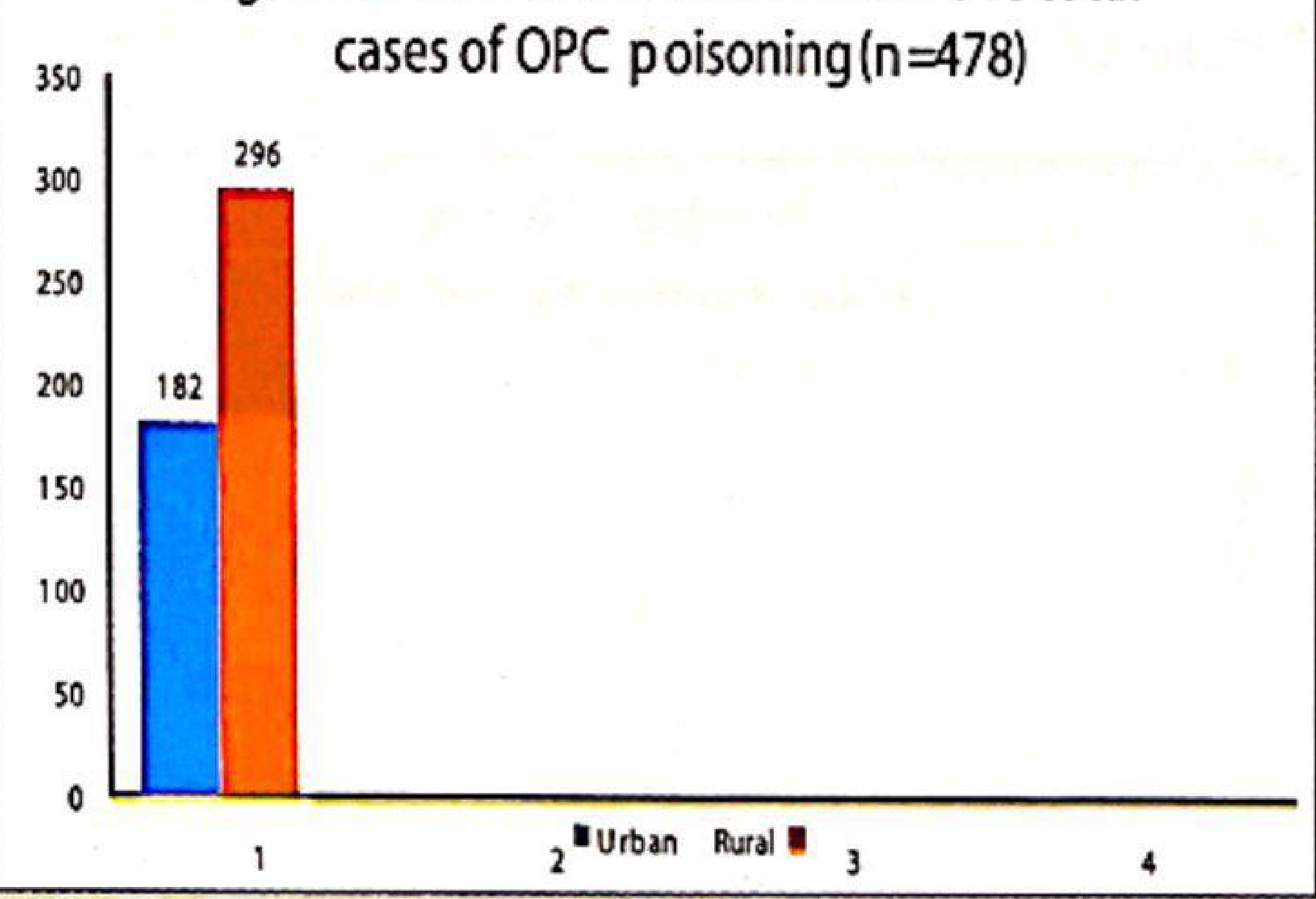

Figure 3 : Distribution according to

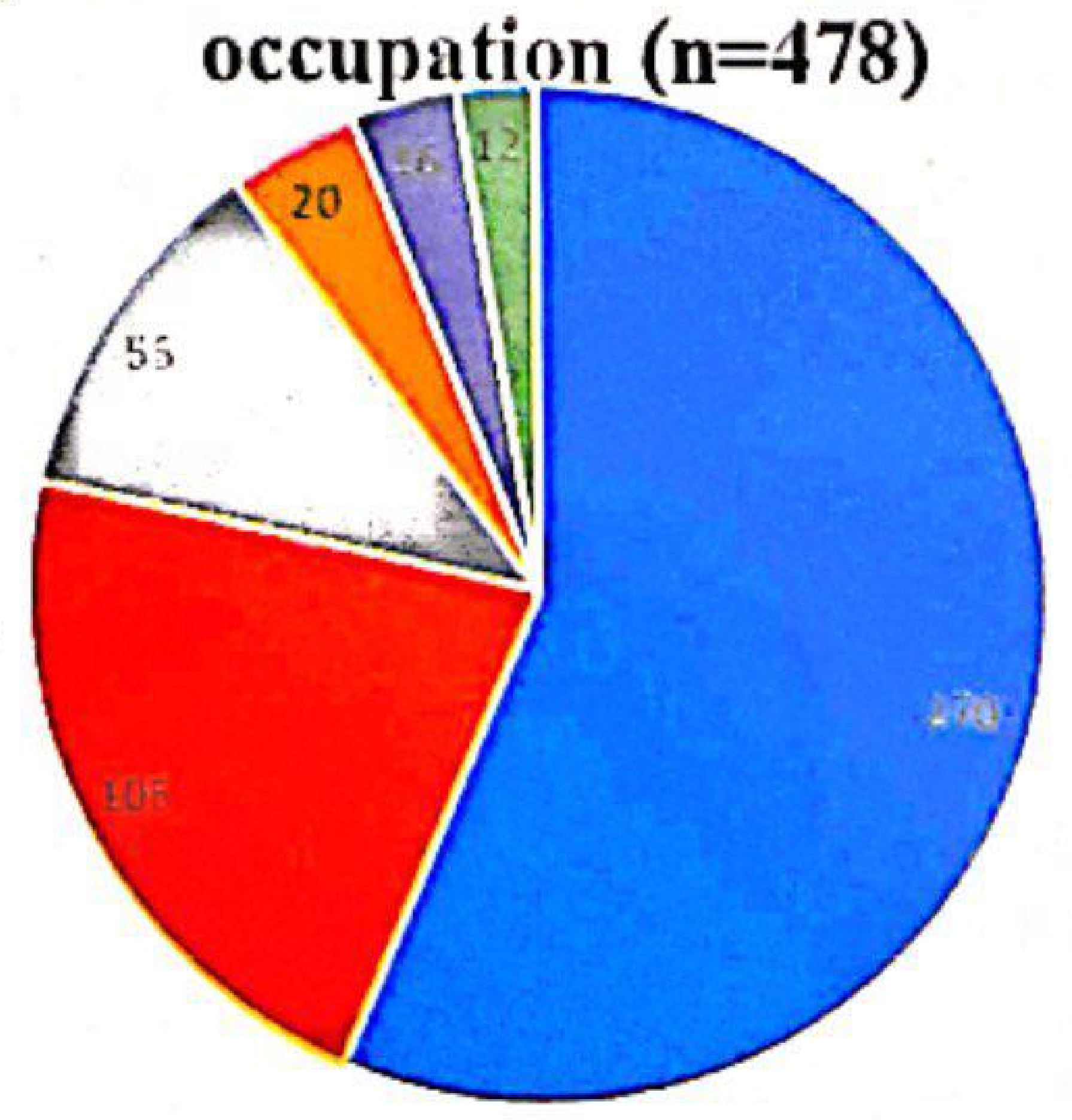

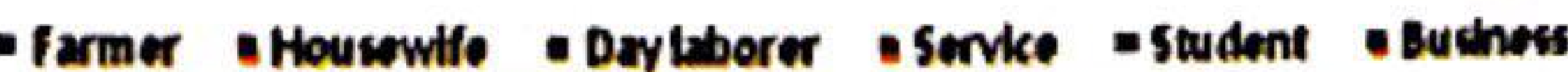




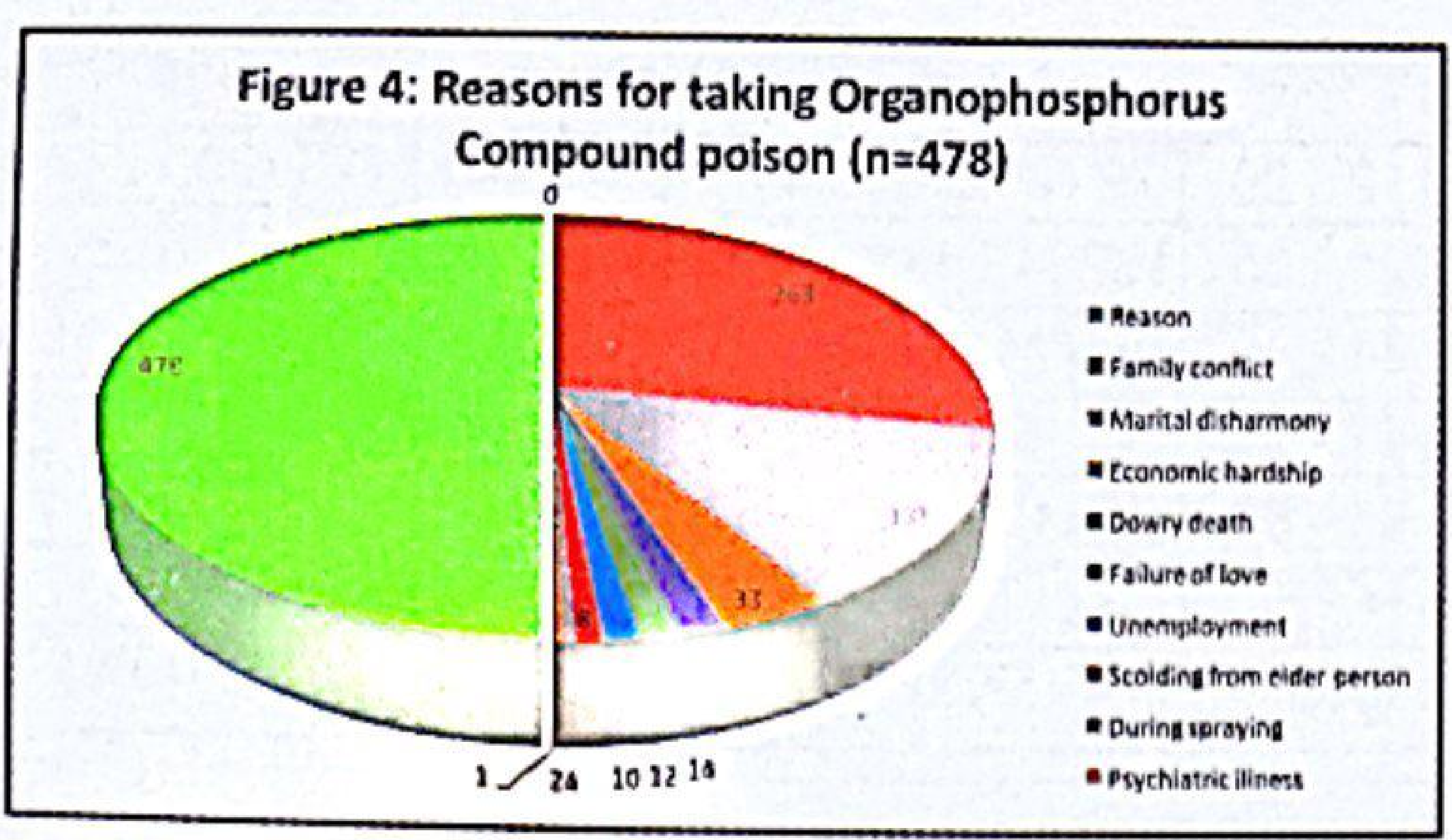

Figure-5: Distribution as per route of administration of poison

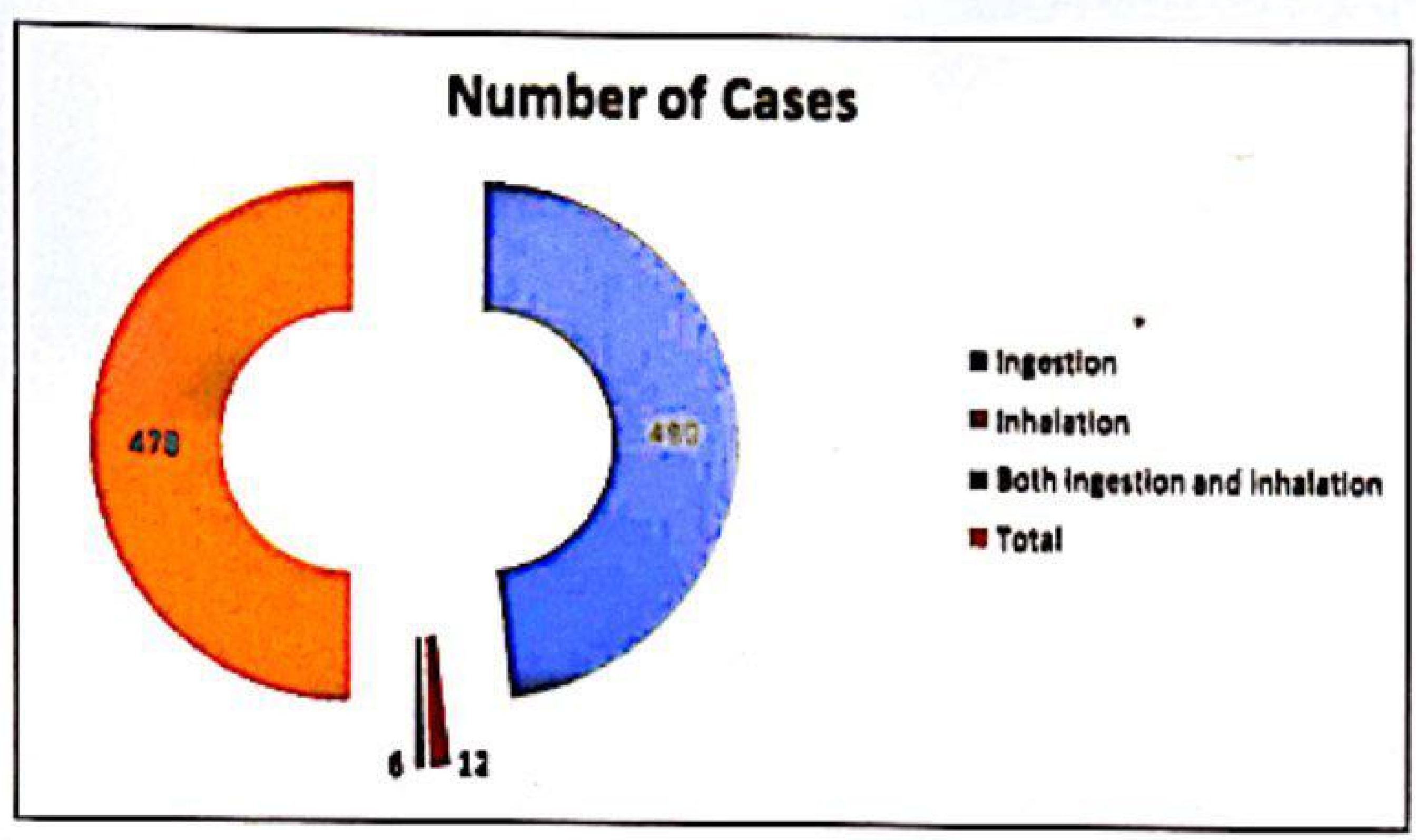

Figure-6: Manner of death

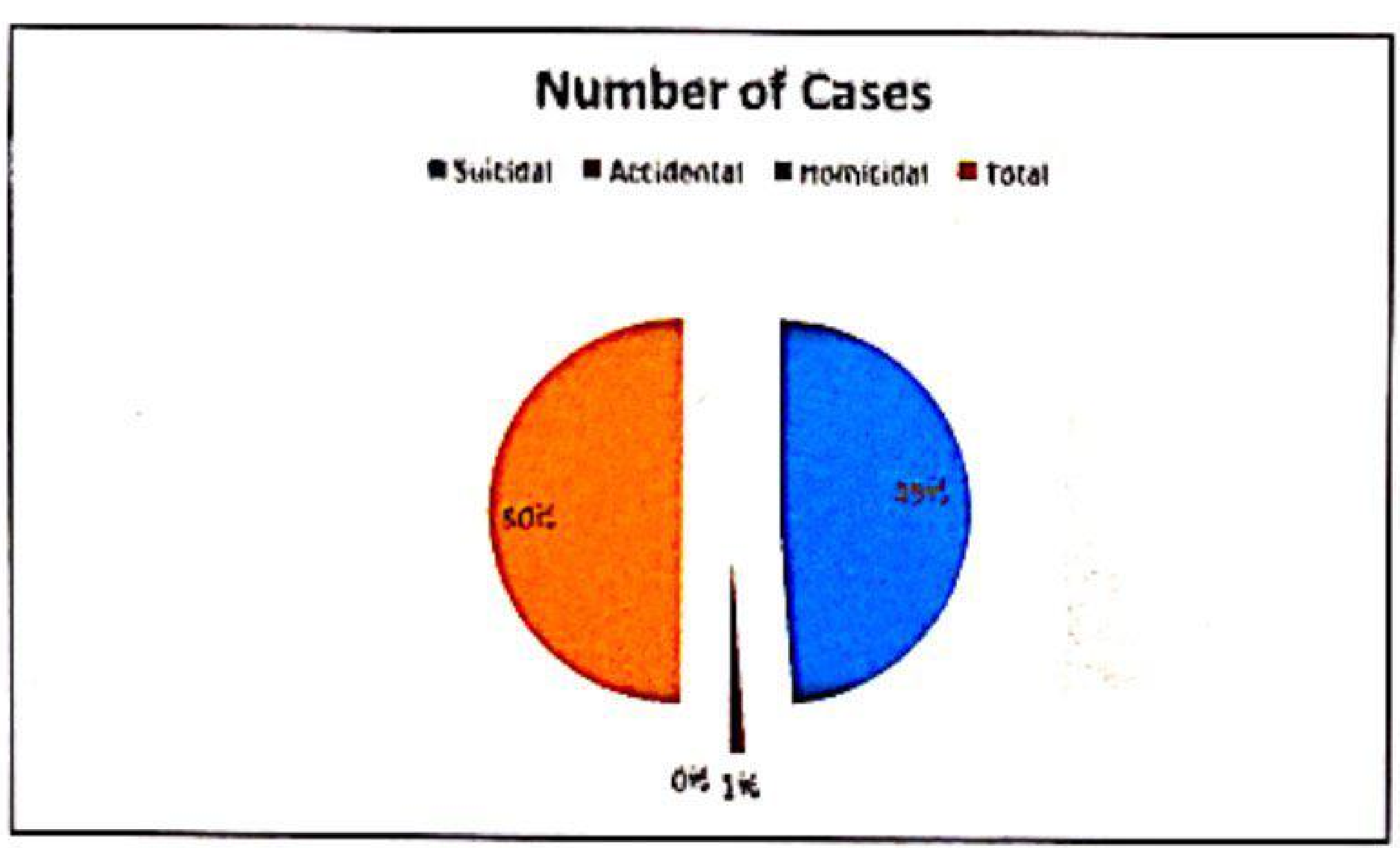

\section{Discussion}

In this study, 4200 post-mortem examinations were done in which 290 cases were of poisoning comprising $(6.9 \%)$ of the total in the year 2009.In India this type of study revealed 163 cases of poisoning comprising $15.11 \%$ of the total 1067 postmortem examinations ${ }^{11}$.

We got 478 cases of poisoning with Organophosphorus Compounds comprising $56 \%$ of the total 852 cases of poisoning. In India similar study was done in which there were 87 cases of OPC poisoning comprising $53.37 \%$ of the total 163 cases of poisoning ${ }^{11}$.
Most of the cases of OPC poisoning were from rural areas i.e 296 cases comprising $61.92 \%$ and the remaining 182 cases from urban areas comprising $38.07 \%$ of the total. An Indian study revealed rural comprising $36.97 \%$ and urban $13.01 \%{ }^{12}$.

Majority of the victims were male. Similar Indian study shows 155 male victims (77.5\%) outnumbered 45 females comprising $22.5 \%$ of the total 200 cases of OPC poisoning ${ }^{8}$.

The most affected age group was $21-30$ years of life for both sexes. Similar study shows that the majority of the victims were from the age group of 21-30 years followed by 51 cases $(25.5 \%)$ from $12-20$ years, 44 cases $(22 \%)$ from $31-40$ years, 13 cases $(6.5 \%)$ from $41-50$ years, 7 cases (3.5\%) from $51-60$ years and the remaining 3 cases from the age group of $>$ 60 years comprising $1.5 \%$ of the total 200 cases of OPC poisoning ${ }^{8}$.

Farmers were the commonest victim followed by housewives, day laborers, service holders, students and businessman. Similar study in India shows that farmers were on top of the list i.e 131 cases comprising $65.5 \%$ followed by 37 cases of housewife (18.5\%), 14 cases of laborer $(7 \%), 9$ cases of students $(4.5 \%), 7$ cases of service holder $(3.5 \%), 1$ case of businessman $(0.5 \%)$ and the remaining 1 case belong to doctor comprising $0.5 \%$ of the total 200 cases of OPC poisoning ${ }^{8}$.

Family conflict was the commonest cause of taking OPC followed by marital disharmony, economic hardship, dowry deaths, failure of love, unemployment, scolding from elder person and guardians, accidentally during spraying as insecticides and psychiatric illness. No cause could be detected in 1 case comprising $0.20 \%$ of the total. Similar study shows that family conflict was on top of the list i.e 59 cases comprising $29.5 \%$, followed by 32 cases of marital conflict (16\%), 24 cases of financial loss (12\%), 22 cases of scolding from elder person or guardians $(11 \%), 11$ cases of physical illness $(5.5 \%), 11$ cases during removal of nozzle of bottle (5.5\%), 10 cases of 
unknown cause $(5 \%), 10$ cases during spraying (5\%), 9 cases of psychiatric illness $(4.5 \%), 4$ cases of academic worries $((2 \%), 3$ cases from under the influence of alcohol $(1.5 \%), 2$ cases after death of only child $(1 \%)$, 1 case of failure of love $(0.5 \%), 1$ case of unemployment $(0.5 \%)$ and the remaining 1 case of dowry death comprising $0.5 \%$ of the total 200 cases of OPC poisoning ${ }^{8}$.

Considering route of administration of poison, ingestion was on top followed by inhalation and combination of both ingestion and inhalation. Similar Indian revealed 198 cases of ingestion comprising $99 \%$ followed by I case of inhalation $(0.5 \%)$ and the remaining 1 case of intravenous poisoning comprising $0.5 \%$ of the total of 200 cases of OPC poisoning ${ }^{8}$.

Suicidal cases outnumbered the list of manner of death followed by accidental. No case of homicide was found with OPC poisoning. Another study in India shows 250 cases of suicide with OPC comprising $87.42 \%$ followed by 36 cases of accident (11.95\%) and only 2 cases of homicide comprising $1.21 \%$ of the total 288 cases of Organophosphorus Compound poisoning ${ }^{13}$.

\section{Conclusion}

Bangladesh is an agricultural country. Suicidal cases by ingestion of insecticides and pesticides are gradually increasing day by day among rural as well as urban people. Illiteracy, unemployment, poverty, emotional instability and family discord are considered to be the prime causes to commit suicide. Proper health education and awareness should be provided for safer use of pesticides to avoid accidental poisoning cases. More research works have to be carried out here in Bangladesh regarding health hazards due to Organophosphorus Compounds poisoning to save the valuable human lives in the future days to come.

\section{Reference}

1. Reddy K.S.N, Essentials of Forensic Medicine and Toxicology, $27^{\text {th }}$ edition, p.p :437

2. Dictionary $M$. Thefreedictionary.com/poisoning.

3. Pillay V.V, Modern Medical Toxicology, $3^{\text {rd }}$ edition, p.p : 2-3.

4. Maiti P.P ${ }^{1}$, Dubey $S^{2}$, Saha $P^{3}$. Study of Various Poisoning : A Review, p.p : 32-35

5. Nandy A, Principles of Forensic Medicine, $2^{\text {nd }}$ edition, 2004, p.p : 492.

6. Patial RK, Bangal SK, Sehagal VK, Chander B. Sphincteric involvement in Organophosphorus poisoning. J Assoc Physicians India, 1991, June, 39 (6): 492-3

7. Ahmed M. ${ }^{1}$, Rahman F.N. ${ }^{2}$, Ashrafuzzaman $\mathrm{M}^{3}$, Chowdhury D.K.P ${ }^{4}$, Ali M. ${ }^{5}$ Overview of Organophosphorus Compound Poisoning in Bangladesh and Medicolegal aspects related to fatal cases. p.p : $38-42$

8. Govsavi V. ${ }^{1}$, Shegokar V.E. ${ }^{2}$, Bhelkar S.M. ${ }^{3}$, Tungikar M. ${ }^{4}$ A Study of Profile of patients with Organophosphorus Compound poisoning at a Teaching Hospital. Vol. 23, p.p : $56-60$

9. Bairy K.L et. Al "Controversies in the management of organophosphate pesticides poisoning" Indian J Pharmacol, 2007, vol. 39, issue-2, p.p : 71-74

10. Ellenhorn M.J. Ellenhorn's Medical Toxicology. Diagnosis and Treatment of Human Poisoning. $2^{\text {nd }}$ edition. Baltimore Md. Lippincott Williams and Wilkins; 1997, p.p : $279-289$

11. Dr. Dalal J.S. ${ }^{1}$, Dr. Goria R.K. ${ }^{2}$, Dr. Aggarwal K.K. ${ }^{3}$, Dr. Thind A.S. ${ }^{4}$, Dr. Sandhu S.S. ${ }^{5}$ Poisoning Trends -A Post-mortem Study 1998, JIAFM, p.p : 27-31

12. Haloi M. ${ }^{1}$, Haloi M.D. ${ }^{2}$, Patowary A. ${ }^{3}$. Death due to poisoning in District of Kamrup, Assam-A Medicolegal Study, JIAFM, January-March 2013, Vol. 35, No1, p.p:42-47

13. Patel D. J. ${ }^{1}$, Tekade P. R. ${ }^{2}$, JProfile of Organophosphorus Poisoning at Maharani Hospital, Jagdalpur, Chhattisgahr: A Three Years Study, JIAFM, April - June 2011, Vol -33, No. 2, p.p : 67-71 